\title{
Historical evolution of the surgical treatment of pancreatic cancer
}

\author{
English version of the article "Evolução histórica do tratamento cirúrgico do câncer \\ de pâncreas" (Sci Med. 2014;24(2):193-201)
}

\author{
Marcelo Garcia Toneto ${ }^{1}$, Maria Helena Itaqui Lopes ${ }^{2}$ \\ ${ }^{1}$ Surgeon of Digestive System, PhD, Associate Professor of Department of Surgery, Faculty of Medicine, PUCRS. Porto Alegre, RS, Brazil. \\ ${ }^{2}$ Gastroenterologist, PhD, Vice-president of Gaucha Association of History of Medicine. Porto Alegre, RS, Brazil.
}

\section{ABSTRACT}

\begin{abstract}
Aims: To review the main historical aspects of the treatment evolution of pancreatic cancer.
Data source: Literature review through PubMed. Selected articles on the history of pancreatic cancer treatment were included.

Summary of findings: Complete surgical resection is the only therapeutic alternative that can offer a cure to patients with pancreatic cancer. However, pancreaticoduodenectomy is one of the most challenging surgical procedures, requiring surgeons with a high level of training for its safe implementation. Several researchers have been involved in the evolution of surgical techniques in pancreatic surgery to reach the levels of safety currently presented by the procedure.

Conclusions: Despite the safety with which pancreaticoduodenectomy is currently performed, postoperative survival in pancreatic cancer is still insufficient, suggesting that operative technical issues are just one of the steps needed to improve the outcome. Better screening methods that enable earlier diagnosis of tumors, identification of high-risk patients and improvements in adjuvant treatment are required to increase the cure rate for this neoplasm.
\end{abstract}

KEY WORDS: pancreatic cancer; pancreaticoduodenectomy; history of medicine; surgery.

Received May, 2014; accepted June, 2014

\section{INTRODUCTION}

Treatment of pancreatic cancer remains a major therapeutic challenge for contemporary medicine. It is the most lethal neoplasm of the gastrointestinal tract, with a five-year survival rate of only $5 \%{ }^{1}$ Estimates from the United States of America indicate that 44,030 new cases of this disease were diagnosed in 2011 and 37,660 people died from this disease. ${ }^{2}$ Complete surgical resection of the tumor is still the only potentially curative therapeutic option for the treatment of pancreatic ductal carcinoma, which is the predominant histological type of neoplasm of this gland. Its location in the retroperitoneum, with complex anatomical relationships with the duodenum, biliary tract, inferior vena cava and aorta, and mainly, the involvement of mesenteric vessels, has hugely delayed the evolution of pancreatic surgery. In addition, the dreaded pancreatic fistula with its devastating consequences for the patient also preventedthe major advances in surgery in the late nineteenth century were reflected in the surgical procedures of the pancreas.

The predominant location of tumors is in the head of the pancreas, which, due to its anatomical characteristics and to preserve surgical oncological principles, should be resected along with the duodenum. This resection, called pancreaticoduodenectomy, is one of the most challenging and specialized procedures performed by gastrointestinal surgeons. Advances in operative techniques and surgical materials, the evolution of anesthesia and intensive care units, the emergence of antibiotics to control infections and great advances in diagnostic and therapeutic radiology have yielded a decrease in mortality rate from above 50\% to less than $3 \%$ in specialized centers for the treatment of this disease. Unfortunately, these surgical advances are still associated with poor outcomes in long-term patient survival due to local recurrences or distant metastases. The increased regionalization of treatment for this disease in recent decades has allowed great 
standardization of the surgical procedure, although numerous controversies in relation to its application remain. $^{3}$

This article presents the historical evolution of the treatment of carcinoma of the pancreatic head and reviews the therapeutic alternatives for the treatment of this disease.

\section{ANATOMICAL CONSIDERATIONS - "THE HERMIT ORGAN"}

The pancreas is anatomically divided in a simple manner, the head, body and tail. Tumors can be located anywhere in the gland. However, when they occur in the body or tail, due to an absence of symptoms, they can progress until important structures are invaded or distant metastases are present, making them unresectable. Those that affect the head of the pancreas frequently invade the common bile duct, causing obstructive jaundice which provides the diagnosis in the majority of cases. The blood supply is derived from the main branches of the celiac trunk and the superior mesenteric artery, and knowledge of this complex anatomy and its variations is mandatory for surgeons wishing to operate in this area. The history of the pancreas may be linked to the history of medicine, taking into account the contributions of anatomy, physiology, microscopy, internal medicine and surgery (Table 1).

Table 1. Chronology of the evolution of knowledge on the pancreas

\begin{tabular}{|c|c|}
\hline 335 BC & Herophilus - Description of the pancreas and duodenum \\
\hline 100 & Ruphos - Description of the organ \\
\hline 1642 & Wirsüng - Identification of the pancreatic duct \\
\hline 1740 & Vater - Description of the duodenal papilla \\
\hline 1744 & Morgagni - $1^{\text {st }}$ known description of pancreatic cancer \\
\hline 1852 & Moyse - Structure of the acinus \\
\hline 1869 & Langerhans - Description of the "islets" - endocrine system \\
\hline 1882 & Trendelenburg - Distal pancreatectomy \\
\hline 1889 & Mering and Minkowski - Removal of the pancreas $=$ diabetes in animals \\
\hline 1898 & Codivilla $-1^{\text {st }}$ attempt at pancreatic head resection without success \\
\hline 1898 & Halsted $-1^{\text {st }}$ successful resection of the ampulla of Vater \\
\hline 1909 & Kausch $-1^{\text {st }}$ successful resection of the pancreatic head ( 2 stage) \\
\hline 1921 & Banting - Discovery of insulin - Nobel prize \\
\hline 1929 & Henrik Dam - Discovery of vitamin K \\
\hline 1937 & Brunschwig - Anatomic pancreaticoduodenectomy \\
\hline 1940 & Whipple $-1^{\text {st }}$ successful resection of the pancreatic head ( 1 stage) \\
\hline 1942 & Rockey - Total pancreatectomy \\
\hline 1973 & Fortner - Regional pancreatectomy \\
\hline 1978 & Traverso and Longmire - pylorus preservation \\
\hline 1993 & Cameron $-1^{\text {st }}$ series of cases without operative mortality \\
\hline 1994 & Gagner - $1^{\text {st }}$ laparoscopic pancreaticoduodenectomy \\
\hline
\end{tabular}

When Harvey described blood circulation, he believed that the pancreas was just a "pad" located behind the stomach to protect the great vessels of the retroperitoneum. It appears that the first person to describe the pancreas was the Greek anatomist and surgeon Herophilusin, one of the founders of the renowned school of medicine of the city of Alexandria, in 335 BC. It took around another 400 years before another eminent anatomist, Ruphos, from the city of Ephesus in Asia Minor, named the gland as the pancreas ("pan" = all, "kreas" = flesh), due to its appearance and the lack of bone and cartilage. This name was used to clearly differentiate it from the mesenteric lymph nodes. Galen was the first to describe the blood circulation of the pancreas and its probable function as a gland. However, he caused confusion and generated delay in the understanding of the physiology of the gland by believing that its function was primarily to protect the retroperitoneum vessels. Galen was considered the greatest authority on anatomy from the $2^{\text {nd }}$ to the $18^{\text {th }}$ century, and as such, this theory was categorically accepted. The years following Galen saw the fall of the Roman Empire, witnessing the entrance of Europe into the "Dark Ages", with the burning of libraries and the loss of almost all the acquired knowledge to date.

In 1629, a young German called Johann Georg Wirsung moved to Padua with the intention of completing his studies in anatomy and medicine. Upon finishing the course, he was invited to remain as a professor of the famous Italian university. On March $2^{\text {nd }}, 1642$, assisted by two of his students, Thomas Bartholin and Moritz Hoffmann, he made the discovery that left his name engraved to immortality. During the autopsy of Zuane Viaro Della Badia, a 30-year-old man who had been hanged the day before, Wirsung found a drainage duct in the pancreas. ${ }^{4}$ Despite not understanding the exact function of the duct, Wirsung knew his discovery was important, and left a drawing of it engraved on a bronze plaque which can still be seen at the Palazzo del Bo, in Padua. After his initial research, Wirsung continued his investigations and confirmed the presence of the duct in humans, fetuses and several animal species. Initially Wirsung and his assistants believed the duct was used for the transfer of chyme from the spleen to the duodenum, however, as no connections with this organ were identified, they then considered it to have some exocrine function of the pancreatic 
gland. From 1865, the prominent Professors Van Horne from the Netherlands, and Riolan from France, began to popularize the name "Wirsungianus" for the main pancreatic duct. ${ }^{4}$ Unfortunately, Wirsung was not aware of this recognition as he had been murdered, in dubious circumstances, about a year after his great discovery. One of the suspicions for his death center around a dispute with his students regarding the true authorship of the finding of the duct. ${ }^{5}$

Following the discovery of Von Haller that the pancreatic duct entered the duodenum in conjunction with the common bile duct, the great French physiologist Claude Bernard determined the digestive function of the pancreas. In 1869, Paul Langerhans published his thesis "Contribution to the microscopic anatomy of the pancreas" in which he described the structure of the islets that now bear his name. Probably due to its location in the retroperitoneum, the pancreas was virtually ignored in ancient times, generating little curiosity and interest, both as an organ and as a host of disease. Even in the early $20^{\text {th }}$ century, the pancreas was still termed as the "hermit organ". Sentences such as "Eat when you can, sleep when you can and don't operate on the pancreas" and "God put the pancreas in the back because he did not want surgeons messing with it", were commonly cited in surgical quotes. ${ }^{6}$

\section{SURGERY AND THE PANCREAS}

Of all the indications for surgery of the pancreas, cancer is the most studied. Autopsy descriptions, starting with Morgagni in 1744 and in the subsequent 200 years, showed that by the time diagnosis was made, the tumor had already invaded neighboring organs making resection impossible. ${ }^{7}$ Symptoms were well recognized: steatorrhea, epigastric pain, vomiting, constipation, anemia and jaundice. Courvoisier published his experience on jaundiced patients in 1890 , which originated the famous law that bears his name: in cases of jaundice due to obstruction of the common bile duct, a contracted gallbladder means the cause is lithiasis; with gallbladder enlargement the jaundice is due to other causes. Praderi ${ }^{8}$ reports that a year earlier in France, Terrier described dilatation of the gallbladder in a patient with pancreatic cancer, from which originated the term "Courvoisier-Terrier's sign".

The deep position of the pancreas in the abdomen, together with hindrance in moving it, and its proximity to important vascular structures, made pancreatic surgery very difficult and dangerous at that time. Only sporadic and isolated reports were found of surgical treatment of large pancreatic cysts, often undertaken inadvertently. In 1882, Friedrich Trendelenburg in Germany performed a planned distal pancreatectomy, with this being the first successful human pancreatic resection. ${ }^{9}$ In addition to these factors, coagulopathy resulting from the lack of vitamin $\mathrm{K}$ absorption secondary to obstructive jaundice, also increased the risks of pancreatic resection. In 1887, almost simultaneously, two surgeons, Kappeler in Switzerland and Monastyrski in Russia, developed the technique of bilioenteric anastomosis between the gallbladder and intestine, with patient survival. About ten years later César Roux developed the method of reconstruction using a Y-shaped isolated segment of the small intestine, separated from the passage of food, and this procedure received his name. The success of this operation led to it becoming recognized as the best alternative for the treatment of jaundice in patients with periampullary neoplasms. ${ }^{10}$ Improvements in surgical techniques in the late nineteenth century, with the first successful gastrectomy, renewed interest in performing more complex resections of the cephalic portion of the pancreatic gland. The first report of a resection of the pancreatic head was probably performed by Giuseppe Ruggi, at the University of Bologna on September 1889 , and involved the enucleation of a tumor mass in the pancreatic head. One of the surgeons in training at the university at that time was a young Italian physician called Alessandro Codivilla. ${ }^{11}$

\section{ALESSANDRO CODIVILLA AND THE FIRST PANCREATICODUODENECTOMY}

Alessandro Codivilla, during his medical training in Bologna, always showed great interest in research and development of new technologies. After accepting the hospital position as chief surgeon in the small town of Imola, Codivilla founded an institute of research and surgery. The institute gained a prominent place in the European surgical community at that time, due to his great experience in the treatment of gastric tumors. The treatment of pancreatic cancer, however, still represented a huge challenge. The reported surgeries were based on wedge resection and enucleation of the pancreas, with high rates of surgical mortality. On February $7^{\text {th }}, 1898$, a 47-year-old farmer was admitted to Codivilla's hospital with suspicion of stomach or pancreatic cancer. Although there are few records of this operation, it is recognized as the first pancreaticoduodenectomy reported in the literature. Operative notes mentioned a pancreatic tumor adhered to the duodenum. The procedure consisted of resection of the pancreatic head, duodenum and part of the 
stomach. Closure of the common bile duct and the distal portion of the duodenum were also performed, followed by a cholecystojejunostomy and Roux-en-Y gastroenterostomy. No treatment of the pancreatic stump was registered. The patient presented serous secretion drainage through the incision, which became milky on the fifth postoperative day (pancreatic fistula?). Death from cachexia was recorded on the $21^{\text {st }}$ postoperative day, with signs of pancreatic insufficiency. One year after the first pancreatic resection, Codivilla received an offer to return to Bologna to become director of an important private institute for orthopedics treatment. This decision led him to abandon general surgery practice at the early age of 37 years. This shift so soon after such an important achievement is probably the reason why details of the pioneering operation were not published by Codivilla himself, but by one of his assistants. Codivilla died at the age of 50 after an operation to treat a bowel obstruction. ${ }^{11}$

Just five days after the operation undertaken by Codivilla, William Stewart Halsted performed the first resection of a tumor located at the ampulla of Vater. ${ }^{12}$ Following propagation of the results of the successful duodenostomy to extract choledochal calculi in the papilla of Vater, a technique originally advocated by Kocher in 1895 , Halsted conceived of a way to apply this procedure to the resection of tumors located in the duodenal ampulla. The patient, a 60 -year-old woman with a history of jaundice, gallbladder distention and hepatomegaly, underwent a transduodenal resection of the ampulla with reanastomosis of the pancreatic duct and common bile duct, in much the same way as it is performed currently. ${ }^{13}$ The patient tolerated the procedure well, but recurrence of the jaundice occurred following removal of the tube used for the cholecystostomy, with further surgery required. The patient died as a consequence of tumor recurrence six months after the procedure. ${ }^{12}$ The result of this surgical procedure, associated with the Halsted's fame, is the adoption, in subsequent years, as the surgery of choice for tumors located in the region.

\section{THE FIRST SUCCESSFUL RESECTION - WALTER KAUSCH}

Walter Kausch, a surgeon born in Germany in 1867, began his medical career in 1890 in psychiatry. After spending time working together with the great surgeon Johannes Mikulicz-Radecki, to whom he became a son-in-law, he migrated to the field of surgery. He became well known for his extensive work in the study of gastric tumors, with over 150 publications on the subject. After practicing on cadavers, Kausch proposed that resection of the pancreatic head could be performed safely if carried out in two stages. In his famous Auguste-Victoria-Krankenhaus clinic in Berlin, a 49-year-old male patient presenting jaundice and weight loss was first submitted to a cholecystoenterostomy to minimize the surgical complications of jaundice. Clinical evolution was good and the patient discharged from hospital four weeks later. The second phase of the operation was performed two months after the initial surgery. It began with wide mobilization of the duodenum, stomach section at the pylorus level, resection of the pancreatic head, section of the common bile duct, and section between the second and third portions of the duodenum. Anastomosis between the pancreatic duct and the third portion of the duodenum was performed. A retrocolic gastroenteroanastomosis restored the digestive transit. The tumor was described as the size of a hazelnut and histology confirmed it was an adenocarcinoma close to the ampulla, without lymph node involvement. A liquid diet was introduced from the first postoperative day together with enemas for fluid replacement, as intravenous hydration was not common at that time. The patient was discharged two months after surgery and died nine months later due to cholangitis. Despite the operation being a revolutionary milestone that took place 25 years before the Whipple operation, it is only known as the Kausch-Whipple surgery in Germany and some other European countries. Kausch died of postoperative complications following surgery for acute appendicitis in $1928 .{ }^{14}$

Another significant progress was made by Ottorini Tenani in 1918, by introducing anastomosis of the main bile duct to the intestine, instead of using the gallbladder. Moreover, he was also a pioneer of blood transfusion and perioperative care, which improved the longterm survival of patients. Adding to this contribution was the finding by surgeon Lester R. Dragstedt, who showed that dogs could survive total excision of the duodenum, proving that it was not a vital organ for animals. ${ }^{10}$ In 1937, Alexander Brunschwig performed the first anatomical resection of the pancreatic head, with section of the pancreatic neck to the right of the mesenteric vessels, associated with total resection of the duodenum. This began the modern era of the pancreaticoduodenectomy. The surgery was performed in two stages, the first consisting of the gastrojejunal anastomosis, cholecystojejunal anastomosis and enteroenterostomy. The patient underwent a further operation thirty days later for excision of the pancreatic head associated to the duodenum and 
the connected duodenal stump. Examination of the specimen confirmed ductal carcinoma with lymph node metastases. The patient died two months later and autopsy revealed peritoneal carcinomatosis and liver metastases. ${ }^{15}$

\section{WHIPPLE AND THE MODERN PANCREATICODUODENECTOMY}

Allen Oldfather Whipple (1881-1963), son of missionary parents, was born in Iran and spent his childhood in the East, a fact that would influence him for life, generatinga great interest in the local medicine, history and art. After coming to the United States he graduated in medicine in 1908. His clinical interest focused on the fusion of anatomical, physiological and surgical knowledge of the pancreas, spleen, portal circulation and biliary tract. In the early 1930s, he founded a multidisciplinary group gathering together surgeons, clinicians, hematologists and pathologists to study several hepatobiliary and splenic diseases. Furthermore, he was a pioneer in the long term followup assessment of patients. ${ }^{16} \mathrm{He}$ became worldwide famous for describing the essential characteristics of insulin-producing tumors of the pancreas, outlining the classic Whipple's triad: spontaneous hypoglycemia, signs and symptoms of hypoglycemia and immediate reversibility with glucose administration.

Whipple ${ }^{17}$ presented in detail his first unsuccessful experience of performing a pancreaticoduodenectomy. In March 1934, his team evaluated a woman with clinical suspicion of carcinoma of the ampulla of Vater. The patient underwent a choledochoduodenostomy to relieve the jaundice. After clinical improvement, she was again submitted to surgery in which the lateral wall of the duodenum and a portion of the pancreatic head were excised. The biliary and pancreatic ducts were sutured to the lateral side of the duodenum wall with catgut sutures. The patient did not respond well and died 30 hours after surgery. The autopsy showed total anastomotic dehiscence as a result of disintegration of the catgut by activated pancreatic fluids. Dr. Mullins, a resident of Whipple, had previously suggested the use of silk and Whipple recognized his own poor choice of thread, learning the lesson for future operations. After further unsuccessful attempts, Whipple proposed, on February 1935, a cholecystogastrostomy as the first stage of operation to relieve jaundice in the treatment of a 49-year-old male patient. All the duodenum and much of the pancreatic head were removed in the second stage, and the pancreatic duct was closed in conjunction with the pancreatic neck. Reconstruction of the digestive transit was performed through a gastrojejunostomy. Silk stitches were used for all the anastomoses. The patient tolerated the surgery well and lived for 25 months until liver metastases caused his death. ${ }^{18}$

With the availability of vitamin $\mathrm{K}$ allowing the correction of bleeding disorders, Whipple began to consider the possibility of performing the procedure in only one stage, which occurred quite by chance. ${ }^{19}$ On March 1940, a gastrectomy was indicated as treatmentof the abdominal mass in a patient with a presumptive diagnosis of gastric carcinoma. After section of the stomach, Whipple was surprised to detect the presence of a 2 to $3 \mathrm{~cm}$ tumor in the pancreatic head. ${ }^{20}$ The favorable thin shape of the patient and absence of jaundice encouraged him to perform the procedure. The entire duodenum, distal portion of the stomach and pancreatic head were removed. The patient response was good and the pathological diagnosis was of a non-functioning insular carcinoma of the pancreas. The patient survived nine years. Although pancreatic anastomosis was not carried out on this occasion, it was done in subsequent patients. This operation became known as the "Whipple operation" thanks to its successful outcome, unlike his previous experiences. During his career, Whipple conducted a pancreaticoduodenectomy on 37 occasions, with a $33 \%$ surgical mortality rate. ${ }^{17}$ The legacy of Whipple was a significant advance in surgery, allowing the pancreas to be operated on in a relatively safe way.

Following the initial success of the "Whipple operation", numerous variations on the surgical technique were proposed to decrease complications of the procedure and to try to achieve better patient survival rates. However, the results in terms of cure were still disappointing. In the following decades, resection was possible in less than $10 \%$ of patients, surgical mortality was above $20 \%$, and cases of a cure were rare. The absence of effective complementary methods such as chemotherapy and radiotherapy induced surgeons to increase the radical nature of the procedure.

\section{TOTAL PANCREATECTOMY}

In the search for improved operative results, total resection of the pancreas was proposed. The first attempt was performed by Rockey ${ }^{21}$ in 1942, but the patient died in the immediate postoperative period. A month later, Priestley ${ }^{22}$ succeeded with a total pancreatectomy indicated for treatment of a patient with insulinoma. The increasing confidence of surgeons with more extensive 
resections, high rates of local tumor recurrence and the concept of multicentricity in pancreatic cancer led to the total pancreatectomy resurfacing as a therapeutic alternative to be investigated. ${ }^{23}$ In addition, total resection of the organ was seen to improve operative complications of surgery due to absence of the dreaded pancreatic anastomosis, the main cause of mortality. More detailed analyses of the results of this operation showed that total resection of the organ did not improve the cure rate in comparison to conventional pancreaticoduodenectomy, originated a difficult to control diabetes, and increased postoperative infectious complications. ${ }^{24}$ The recent increase in diagnosis of intraductal papillary mucinous neoplasm (IPMN) of the pancreas, a disease that present in a multifocal form in many patients, motivated interest in the total pancreatectomy. From an oncological viewpoint, only IPMNs of the main duct, multifocal tumors and metastases to the pancreas are current indications for total pancreatectomy. Additionally, this procedure may be indicated for central located carcinomas when conventional resection margins are questionable or compromissed..$^{25,26}$

\section{REGIONAL PANCREATECTOMY}

Even with the rise of the total pancreatectomy as a way to reduce high rates of tumor recurrence in operated patients, the tumor resection rates were still very low $(<15 \%)$, and one factor that greatly hindered resection of the tumor was vascular infiltration, especially of the mesenteric-portal venous complex and the superior mesenteric artery. These findings led Fortner $^{27}$ to propose a more aggressive resection, developing a surgical procedure that became known as regional pancreatectomy. This operation consisted of resection of the portal vein segment en bloc with the pancreas. Furthermore, the base of the transverse mesocolon and peripancreatic tissues were removed, and opening of the Gerota fascia performed with cleaning of the tissues around the renal hilum, inferior vena cava and aortic artery. The surgery also involved dissection of the hepatic artery, as well as the celiac trunk and superior mesenteric artery. About 10 years later, Fortner ${ }^{28}$ published the results of his personal series of 61 patients. The average operative time for this procedure was 10 hours and 30 minutes, varying from 8 to 29 hours, while the estimated blood loss was around 6 liters. The magnitude of the procedure led to a long hospitalization period (average 41 days). Even though the operation had a surprising $29 \%$ survival rate for that time, the $21 \%$ mortality rate prevented this operation to spread out beyond a small group of highly skilled surgeons, who practiced it for a short period of time. However, modification of the Fortner procedure, by limiting to resection of the portal vein or mesenteric vessels when invaded, without extensive lymphadenectomy, has been performed by contemporary surgeons with excellent results. ${ }^{29}$

\section{THE CONTROVERSY OF THE 1970s}

The following decades witnessed the widespread useof the pancreaticoduodenectomy, although it remained a "dangerous" surgery with a high mortality rate. In the early 1970 s, the famous surgeon George Crile, head of surgery at the Cleveland Clinic, banned the operation from his department due to a mortality rate above $20 \%$ and 5-year survival rate below 5\%. ${ }^{30}$ Several important physicians at that time declared they had never seen a patient with a pancreatic tumor cured. ${ }^{31}$ Studies comparing tumor resection with palliative procedures showed the survival rates to be the same, with much lower costs for palliative surgery. ${ }^{32}$ The safety of the pancreaticoduodenectomy was only confirmed following the publication of studies without operative mortality, conducted in large centers of excellence in the 1990s. ${ }^{33,34}$ Currently, many hospitals perform more than 100 pancreatoduodenectomies per year, with mortality rates below $5 \%$ and 5-year survival rates of approximately $20 \%{ }^{35}$ These results probably relate to improved perioperative care and the refinement of surgical technique, with minimal blood loss (the majority of patients nowadays are operated on without transfusion). Patient age is no longer a contraindication for the procedure and some studies have shown the safety of the surgery in patients more than 80 years of age. ${ }^{36}$

\section{PYLORUS PRESERVATION}

During the early 1970 s, the complications associated with the procedure decreased, thus increasing its indication. Among the diseases treated with this method was chronic pancreatitis. Apparently, surgical resection of the pancreatic head could successfully control pain in these patients. However, the surgeon William Longmire Jr., well known for his technical innovations in gastrointestinal surgery, disagreed with the need to remove half the stomach to treat a disease restricted to the pancreas. Fear of the diagnosis of marginal ulcers that could occur with economic resection of the gastric antrum was the main justification for gastrectomy associated with pancreatic resection. 
In 1977, with the intention of making the procedure more physiological, Longmire Jr. and his resident William Traverso performed a pancreaticoduodenectomy with preservation of the pylorus. ${ }^{37}$ The procedure showed an increase in quality of life and weight maintenance in the later postoperative period of Traverso's patients. ${ }^{38}$ Although not initially indicated for the treatment of pancreatic cancer, the better quality of life associated with this procedure increased its indication, becoming accepted by the majority of surgical teams treating this disease. Analysis of a series of cases at Johns Hopkins Hospital showed that $70 \%$ of patients undergoing surgery for neoplasm of the pancreas at that institution were operated on using this technique. ${ }^{39}$

\section{CURRENT PERSPECTIVES}

The years 2000s allowed analysis of the influence of the centralization of complex surgical procedures in specialized institutions. While the surgical mortality rate for the pancreaticoduodenectomy was below $2 \%$ at the Johns Hopkins Hospital, the rate approached $20 \%$ for the other 45 hospitals in Maryland state. ${ }^{40}$ The practical application of that knowledge led to a change around ten years later, with the procedure being centralized in the state and the John Hopkins Hospital conducting more than $60 \%$ of the operations. Furthermore, there has been great interest in evaluating patient quality of life for those undergoing a procedure of such magnitude. From a surgical viewpoint, recovery of gastrointestinal function and patient nutritional status may be affected by delayed gastric emptying and the problems associated with exocrine insufficiency. ${ }^{41}$ Additionally, diabetes mellitus can arise with the need for oral medication or insulin use. ${ }^{42}$ However, a comparison of patients undergoing pancreatic resection with those having laparoscopic cholecystectomy and the healthy controls showed that although some patients in the pancreatectomy group presented complaints about weight loss, fatigue, diabetes and abdominal pain, their quality of life was similar to the control group, generally returning to satisfactory levels six months after surgery. ${ }^{43}$

The great advances introduced by minimally invasive surgery took time to become available to surgeons operating on the pancreas. The intrinsic complexity of the operation, associated with the need for a surgeon highly trained in laparoscopic techniques and experienced in the procedure, has led to resection of the pancreatic head still being an uncommon procedure. Although the first description of the performance by Gagner of a totally laparoscopic pancreaticoduodenectomy was in $1994,{ }^{44}$ it is recently that a few series of successful cases have begun to be published..$^{45}$ The emergence of studies showing the advantages of treatment with chemotherapy and/ or radiotherapy, both as adjuvant and neoadjuvant therapy, and allowing increased resectability rates, also demonstrates that treatment of this disease can begin to show more promising results. ${ }^{46,47}$

\section{FINAL CONSIDERATIONS}

Pancreatic resection for the treatment of tumors can now be considered safe. However, the ultimate achievement of good results still seems distant. Effective screening measures that enable earlier diagnosis, identification of patients at risk, and the search for better results from complementary treatments, would appear to be the most important steps for improving the cure rate for this disease. Knowledge of the history of this complex operation should motivate reflection by all those involved in the treatment of pancreatic cancer in order to avoid the same mistakes as our predecessors. Surgery is still a fundamental component for the treatment of these tumors, and the aim of the surgeons is to remove the tumor and keep the patients in good condition, allowing debilitating complementary treatments to take place.

\section{REFERENCES}

1. Hariharan D, Saied A, Kocher HM. Analysis of mortality rates for pancreatic cancer across the world. HPB (Oxford). 2008;10:58-62. http://dx.doi.org/10.1080/13651820701883148

2. Siegel R, Ward E, Brawley O, Jemal A. Cancer statistics, 2011: the impact of eliminating socioeconomic and racial disparities on premature cancer deaths. CA Cancer J Clin. 2011;61(4):212-36. http://dx.doi.org/10.3322/caac.20121

3. Evans DB, Farnell MB, Lillemoe KD, Vollmer C Jr, Strasberg SM, Schulick RD. Surgical treatment of resectable and borderline resectable pancreas cancer: expert consensus statement. Ann SurgOncol. 2009;16(7):1736-44. http://dx.doi.org/10.1245/s10434-009-0416-6

4. Bassi C, Malleo G. The unsolved mystery of Johann Georg Wirsung and of (his?) pancreatic duct.Surgery. 2011;149(1):153-5. http://dx.doi.org/10.1016/j.surg.2010.07.049 
5. Carter R. Assassination of Johann Georg Wirsung (1589-1643): mysterious medical murder in Renaissance Padua. World J Surg. 1998;22:324-6. http://dx.doi.org/10.1007/s002689900389

6. Busnardo AC, DiDio LJ, Tidrick RT, Thomford NR. History of the pancreas. Am J Surg. 1983;146(5):539-50. http://dx.doi.org/10.1016/00029610(83)90286-6

7. McClusky III DA, Skandalakis LJ, Colborn GL, Skandalakis JE. Harbinger or Hermit? Pancreatic Anatomy and Surgery through the Ages - Part 2. World J Surg. 2002;26:1370-81. http://dx.doi.org/10.1007/s00268-002-1239-9

8. Praderi RC. History of pancreatic surgery. In: Trede M, Carter DC, ed. Surgery of the Pancreas. New York: Churchill Livingstone; 1993.

9. Schnelldorfer T, Adams DB, Warshaw AL, Lillemoe KD, Sarr MG. Forgotten pioneers of pancreatic surgery. Ann Surg. 2008;247: 191-202. http://dx.doi.org/10.1097/SLA.0b013e3181559a97

10. Howard JM. History of pancreatic head resection - the evaluation of surgical technique. Am J Surg. (Suppl) 2007;194:S6-S10. http://dx.doi.org/10.1016/j.amjsurg.2007.05.029

11. Schnelldorfer T, Sarr MG. Alessandro Codivilla and the First Pancreatoduodenectomy. Arch Surg. 2009;144(12):1179-84. http://dx.doi. org/10.1001/archsurg.2009.219

12. Halsted WS. Contributions to the surgery of the bile passages, especially of the common bile-duct.Boston MedSurg J. 1899;141:645. http://dx.doi.org/10.1056/NEJM189912281412601

13. Souza HP, Alves JM, Toneto MG, Gabiatti G, Pandolfo G. Papiloduodenectomia como Alternativa Terapêutica para Tumores Papilares. Rev Col Brasil Cir. 1998;25(6):423-6. http://dx.doi.org/10.1590/S0100-69911998000600012

14. Are C, Dhir M, Ravipati L. History of pancreaticoduodenectomy: early misconceptions, initial milestones and the pioneers. HPB (Oxford). 2011;13(6):377-84. http://dx.doi.org/10.1111/j.1477-2574.2011.00305.x

15. Brunschwig A. Resection of head of pancreas and duodenum for carcinoma - pancreatoduodenectomy. Surg Gynecol Obstet. 1937;65: 681-4.

16. Chen TS, Chen PS. The Whipples and their legacies in medicine. Surg Gynecol Obstet. 1993;176:501-6.

17. Whipple AO. A reminiscence: pancreaticoduodenectomy. Surgery. 1963;20:221-5.

18. Whipple AO, Parsons WB, Mullins CR. Treatment of carcinoma of the ampulla of Vater. Ann Surg. 1935;102:763-9. http://dx.doi. org/10.1097/00000658-193510000-00023

19. Peters JH, Carey LC. Historical review of pancreatoduodenectomy. Am J Surg. 1991;161:219-25. http://dx.doi.org/10.1016/00029610(91)91134-5

20. Whipple AO. Pancreaticoduodenectomy for islet carcinoma. Ann Surg. 1945;121:847-52. http://dx.doi.org/10.1097/00000658-19450600000008

21. Rockey EW. Total pancreatectomy for carcinoma: case report. Ann Surg. 1943;118(4):603-11. http://dx.doi.org/10.1097/00000658194310000-00008

22. Priestley JT, Comfort MW, Radcliffe J. Total pancreatectomy for hyperinsulinism due to an islet-cell adenoma: survival and cure at sixteen months after operation presentation of metabolic studies. Ann Surg. 1944;119(2):211-21. http://dx.doi.org/10.1097/00000658194402000-00004

23. Pliam MB, ReMine WH. Further evaluation of total pancreatectomy. Arch Surg. 1975;110:506-12. http://dx.doi.org/10.1001/ archsurg.1975.01360110052010

24. Sarr MG, Behrns KE, van Heerden JA. Total pancreatectomy. An objective analysis of its use in pancreatic cancer.Hepato-Gastroenterology. 1993;40:418-21.

25. Sohn TA, Yeo CJ, Cameron JL, Hruban RH, Fukushima N, Campbell KA, Lillemoe KD. Intraductal papillary mucinous neoplasms of the pancreas: An updated experience. Ann Surg. 2004;239:788-97. http://dx.doi.org/10.1097/01.sla.0000128306.90650.aa

26. Müller MW, Friess H, Kleeff J, Dahmen R, Wagner M, Hinz U, Breisch-Girbig D, Ceyhan GO, Büchler MW. Is there still a role for total pancreatectomy? Ann Surg. 2007;246:966-74. http://dx.doi.org/10.1097/SLA.0b013e31815c2ca3

27. Fortner JG. Regional resection of cancer of the pancreas: a new surgical approach. Surgery. 1973;73:307-20.

28. Fortner JG. Regional pancreatectomy for cancer of the pancreas, ampulla, and other related sites.Tumor staging and results. Ann Surg. 1984;199(4):418-25. http://dx.doi.org/10.1097/00000658-198404000-00008

29. Harrison LE, Klimstra DS, Brennan MF. Isolated portal vein involvement in pancreatic adenocarcinoma:a contraindication for resection? Ann Surg.1996;224:342-7. http://dx.doi.org/10.1097/00000658-199609000-00010

30. Crile G Jr. The advantages of bypass operations over radical pancreatoduodenectomy in the treatment of pancreatic carcinoma. SurgGynecolObstet 1970;130:1409-53.

31. Gudjonsson B. Cancer of the pancreas: 50 years of surgery. Cancer. 1987;60:2284-303. http://dx.doi.org/10.1002/1097-0142(19871101) 60:9<2284::AID-CNCR2820600930>3.0.CO;2-V

32. Shapiro TM. Adenocarcinoma of the pancreas: a statistical analysis of biliary bypass vs Whipple resection in good risk patients. Ann Surg. 1975;182(6):715-21. http://dx.doi.org/10.1097/00000658-197512000-00010

33. Trede M, Schwall G, Saeger HD. Survival after pancreatoduodenectomy. 118 consecutive resections without an operative mortality. Ann Surg. 1990;211(4):447-58. http://dx.doi.org/10.1097/00000658-199004000-00011

34. Cameron JL, Pitt HA, Yeo CJ, Lillemoe KD, Kaufman HS, Coleman J.One hundred and forty-five consecutive pancreaticoduodenectomies without mortality. Ann Surg. 1993;217:430-5. http://dx.doi.org/10.1097/00000658-199305010-00002 
35. Yeo CJ, Cameron JL, Sohn TA, Lillemoe KD, Pitt HA, Talamini MA, Hruban RH, Ord SE, Sauter PK, Coleman J, Zahurak ML, Grochow LB, Abrams RA. Six hundred fifty consecutive pancreaticoduodenectomiesin the 1990s: pathology, complications, and outcomes. Ann Surg 1997;226:248-57. http://dx.doi.org/10.1097/00000658-199709000-00004

36. Makary MA, Winter JM, Cameron JL, Campbell KA, Chang D, Cunningham SC, Riall TS, Yeo CJ. Pancreaticoduodenectomy in the very elderly. J Gastrointest Surg. 2006;10(3):347-56. http://dx.doi.org/10.1016/j.gassur.2005.12.014

37. Traverso LW, Longmire WP. Preservation of the pylorus in pancreaticoduodenectomy.SurgGynecolObstet 1978;146:959-62.

38. Traverso LW, Longmire WP. Preservation of the pylorus in pancreaticoduodenectomy - a follow-up evaluation. Ann Surg 1980;192: 306-10. http://dx.doi.org/10.1097/00000658-198009000-00005

39. Sohn TA, Yeo CJ, Cameron JL, et al. Resected adenocarcinoma of the pancreas -616 patients: results, outcomes, prognostic indicators. J Gastrointest Surg. 2000;4:567-79. http://dx.doi.org/10.1016/S1091-255X(00)80105-5

40. van Heek NT, Kuhlmann KF, Scholten RJ, de Castro SM, Busch OR, van Gulik TM, Obertop H, Gouma DJ. Hospital volume and mortality after pancreatic resection: a systematic review and an evaluation of intervention in the Netherlands. Ann Surg. 2005;242(6):781-8. http://dx.doi.org/10.1097/01.sla.0000188462.00249.36

41. Ohtsuka, T.; Tanaka, M.; Miyazaki, K. Gastrointestinal function and quality of life after pylorus-preserving pancreatoduodenectomy. J Hepatobiliary Pancreat Surg. 2006;13:218-24. http://dx.doi.org/10.1007/s00534-005-1067-z

42. Fitzsimmons, D.; Johnson, C.D. Quality of life after treatment of pancreatic cancer. Langenbecks Arch Surg. 1998;383:145-51 http://dx.doi.org/10.1007/s004230050106

43. Huang JJ, Yeo CJ, Sohn TA, Lillemoe KD, Sauter PK, Coleman J, Hruban RH, Cameron JL. Quality of life and outcomes after pancreaticoduodenectomy. Ann Surg. 2000;231(6):890-8. http://dx.doi.org/10.1097/00000658-200006000-00014

44. Gagner M, Pomp A. Laparoscopic pylorus preserving pancreatoduodenectomy. SurgEndosc. 1994;8(5):408-10. http://dx.doi.org/10.1007/ bf00642443

45. Kendrick ML, Cusati D. Total laparoscopic pancreaticoduodenectomy: feasibility and outcome in an early experience. Arch Surg. 2010;145(1):19-23. http://dx.doi.org/10.1001/archsurg.2009.243

46. Oettle $\mathrm{H}$, Post $\mathrm{S}$, Neuhaus $\mathrm{P}$, et al. Adjuvant chemotherapy with gemcitabine vs observation in patients undergoing curative-intent resection of pancreatic cancer: a randomized controlled trial. JAMA. 2007;297(3):267-77. http://dx.doi.org/10.1001/jama.297.3.267

47. Pisters PW, Wolff RA, Janjan NA, Cleary KR, Charnsangavej C, Crane CN. Preoperative paclitaxel and concurrent rapid-fractionation radiation for resectable pancreatic adenocarcinoma: toxicities, histologic response rates, and event-free outcome. J ClinOncol. 2002;20(10):2537-44. http://dx.doi.org/10.1200/JCO.2002.11.064 